\title{
STUDY OF FACTORS DETERMINING OUTCOMES IN THE HOSPITALIZED PATIENTS WITH ACUTE EXACERBATION OF CHRONIC OBSTRUCTIVE PULMONARY DISEASE (COPD)
}

\author{
Sijapati $\mathrm{MJ}^{1}$, Bhatta $\mathrm{N}^{2}$, Khanal $\mathrm{B}^{3}$, Lamsal $\mathrm{M}^{4}$, Chaudhary $\mathrm{S}^{5}$
}

\begin{abstract}
BACKGROUND: Chronic Obstructive Pulmonary Disease (COPD) is a major cause of mortality and morbidity across the world. Information related to the factors associated with COPD exacerbation and factors determining outcome in hospitalized patient with acute exacerbation of COPD are very important for effective long-term management of this disease. Within this background we attempted to study the factors determining outcome in hospitalized patients with acute exacerbation of COPD.
\end{abstract}

METHODS: The study was prospective observational study. Hundred consecutive patients hospitalized with acute exacerbation of COPD were prospectively assessed.

RESULTS: Patients required mechanical ventilation and Intensive Care Unit (ICU) transfer were 17 (17\%). Patients with hypercapnia pCO2 [ $(80.24 \pm 10.76 \mathrm{mmHg} \mathrm{P}=0.001], \mathrm{pH}[(7.24 \pm 0.062) \mathrm{P}=0.004]$ with type 2 respiratory failure required ICU transfers with mechanical ventilatory support and these variables were statistically significant in univariate analysis. Patients who were in COPD stage III $\left(\mathrm{FEV}_{\mathrm{I}} / \mathrm{FVC}\right.$ ratio $\left.<0.35\right)$ and having the poor arterial blood gas parameters $\mathrm{pH}$ (7.24 \pm 0.02$) \mathrm{P}=0.001, \mathrm{pCO} 2[(76.5 \pm 13.12 \mathrm{mmHg}, \mathrm{P}=0.006]$ had bad prognosis. The patients with Acute Exacerbation of Chronic Obstructive Pulmonary Disease (AECOPD) who were smokers and exposed to indoor air pollution due to use of biomass fuels had poor outcomes.

CONCLUSION: Patients with AECOPD hospitalized in a tertiary care center in a developing country suggest that $\mathrm{FEV}_{1} / \mathrm{FVC}$ impairment, decreased $\mathrm{pH}$, increased $\mathrm{pC} 02$, current smoking status and presence of biomass exposure are associated with prolonged hospitalization, ICU admission and death.

\section{KEYWORDS: COPD, AECOPD}

1. Consultant Physician,Department of Internal Medicine, Norvic International Hospital,Thapathali, Kathmandu, Nepal

2. Professor, Department of Internal Medicine, B.P.Koirala Institute of Health Sciences, Dharan, Nepal

3. Professor, Department of Microbiology, B.P.Koirala Institute of Health Sciences, Dharan, Nepal

4. Professor, Department of Biochemistry, B.P.Koirala Institute of Health Sciences, Dharan, Nepal

5. Associate Professor, Department of Internal Medicine, Universal College of Medical Sciences \& Teaching Hospital, Bhairahawa, Nepal

For Correspondence

Dr. Milesh Jung Sijapati

Consultant Physician,

Department of Internal Medicine,

Norvic International Hospital, Thapathali, Kathmandu, Nepal.

Email: mileshjung@hotmail.com 


\section{INTRODUCTION}

COPD is a major cause of mortality and morbidity across the world. COPD is the fourth leading cause of death in the world according to the study published by world health organization $(\mathrm{WHO})^{1}$ Burden of the disease is projected to increase in the next 20 years. ${ }^{2,3} \mathrm{AECOPD}$ are important feature in the natural history of COPD. Hospitalizations for acute exacerbation usually occur in the later stage of COPD and represents more than $70 \%$ of all COPD related medical costs. It has been estimated that almost $35-40 \%$ of the total per capita health care cost of COPD are accounted for exacerbations only. Severe exacerbation requiring hospitalization are responsible for a large share of this cost and among these, treatment cost for those who require ICU admission is highest. The length of stay and ICU care is an outcome of greatest interest in developing countries because it puts enormous economic burden on patient, families and health system and is an important index for resource utilization.

Most of the studies on ambulatory COPD patients have focused on identification of factors associated either with relapse after treatment for acute exacerbation ${ }^{5.8}$ or with poor evolution of the exacerbated disease, ${ }^{9}$ and only few dealt with factors predicting mortality after admission to hospital for an exacerbation. ${ }^{10-12}$ Moreover, recent studies have focused on physiologic measures such as pulmonary artery pressure to try to elucidate the increased risk of hospitalization of patients with COPD.$^{13}$ However the possibility of predicting the risk of recurrent exacerbations or hospital admission based on clinical and functional data has only seldom been assessed in small populations. ${ }^{14}$

Information related to the factors associated with COPD exacerbation and factors determining outcome in hospitalized patient with AECOPD are very important for effective longterm management of this disease. Although the clinical outcomes of AECOPD hospitalized patients can be easily recorded, the study related to information about factors related to COPD exacerbation and outcome of AECOPD in hospitalized patients is lacking in Nepal. Within this background we attempted to study the factors determining outcome in hospitalized patient with AECOPD. Our study mainly focus at few identifiable outcomes for patients with acute exacerbation of COPD mainly length of hospital stay, ${ }^{1}$ requirement of intensive care with or without assisted ventilation, ${ }^{2}$ readmission rates, ${ }^{3}$ death and other factors related to mortality in COPD patients.

\section{MATERIALS AND METHODS}

The study was conducted in the Department of Internal Medicine B.P Koirala Institute of Health Sciences, Dharan from $15^{\text {th }}$ February 2005 to $15^{\text {th }}$ Feb 2006 for a period of one year. It was a prospective observational study. Hundred consecutive patients hospitalized with AECOPD were prospectively assessed. Study was cleared by ethical review committee of the institute and written informed consent was taken from all the patients.

COPD was defined as per American Thoracic Society (ATS) guidelines. The key indicators for considering a COPD as diagnosis was chronic cough, chronic sputum production, dyspnea that was progressive (worsens over time)/persistent (present every day)/Worse on exercise/Worse during respiratory infection \& history of exposure to risk factors like tobacco smoke, occupational dusts and chemicals or smoke from home cooking and heating fuel in a patients aged 45 years or above as per ATS guidelines. The diagnosis was confirmed by spirometry.

Severity of COPD was classified based on airflow obstruction using ATS criteria for forced expiratory volume in 1 second (FEV1) as percent of predicted. Stage I: Mild airflow obstruction with FEV1 $\geq 50 \%$ predicted, Stage II: Moderate airflow obstruction with FEV1 35 to $49 \%$ predicted, Stage III: Severe airflow obstruction with FEV1 $<35 \%$ predicted.

The majority of pulmonary function test was done within 3 days of hospitalization or whenever patients were fit to perform the test. AECOPD was defined as the presence of any one of the following three symptoms : (Antonisen Criteria)

1. Increased cough \& sputum volume 2 . Increased sputum purulence 3. Increased dyspnea.

In addition, patients had one or more symptoms of fever, malaise, fatigue and chest congestion. Severity of an AECOPD was defined as type 1 when patients had all three symptoms, type 2 when patients had any 2 out of three symptoms and type 3 when patients had any one out of three symptoms. Other cases of chronic cough were excluded which includes Lung Cancer, active Pulmonary Tuberculosis, Bronchial Asthma, Interstitial Lung Disease and Bronchiectasis.

A detailed socio-demographic data for every patient presenting with AECOPD was collected either from emergency or OPD. Information was recorded in structured Performa. The demography included age, sex, smoking history, and history of exposure to biomass smoke, visit to health care facility with respiratory symptoms in the past, 
history of pulmonary tuberculosis, use of respiratory medication as inhaler, steroids, domiciliary oxygen and comorbid conditions. Detailed signs and symptoms, chest radiograph, sputum for gram stain and culture, arterial blood gases, Total Leucocyte Count (TLC), Serum albumin, Erythrocyte Sedimentation Rate (ESR), C-Reactive Protein (CRP), pulse oximetry were done at the time of admission. Arterial Blood Gases (ABG) and chest radiograph were repeated before the discharge. The treatment and investigation decisions were ordered by individual treating physician and treatment generally reflected the treatment practice for AECOPD in our hospital. Spirometry was done preferably within three days of hospitalization or as soon as the patient could perform the test. Main variables considered in statistical analysis were age, smoking history, exposure to biomass smoke, respiratory symptoms, comorbid conditions, ABG, CXR, spirometry and performance status by 6 minutes walk test. Beside these other important variables mentioned in methodology were also considered.

The treatment response to acute exacerbation to COPD was recorded as follows:

1. Hospitalized for $\leq 5$ days \& discharged

2. Hospitalized for $5 \geq$ days $\&$ discharged

3. Admission to ICU after hospitalization requiring mechanical ventilation

4. Readmission after discharge

5. Death

Patient was considered readmitted if they return after four weeks of discharge with similar respiratory symptoms. All data were expressed as the mean \pm standard deviation (SD). Data were entered on "Excel" master sheet. Considering the importance of smoking \& exposure to indoor air pollution by the use of biomass in etio-pathogenesis of COPD patients were categorized into following four groups (Biomass exposure \& smoker, Biomass exposure only, Smoker only \& No biomass or smoker). Predictors of outcomes were compared among these four groups. All statistical analysis was performed using a statistical software package (SPSS for windows. Version 9.0). Nominal variables were compared using Chi- square test or Fisher's exact test. Comparisons between groups were performed using analysis of variance. To determine various predictors of death following hospitalization of AECOPD, the analysis was performed in two stages. For this quantitative variables were categorized. Variables showing statistically significant association with the outcomes at $\mathrm{p}<0.20$ were considered as candidate variable for inclusion in the multivariate model. Stepwise multivariate logistic regression was performed with potential candidate variables as the co-variates. All the statistical tests performed are two tailed; $\mathrm{p}<0.05$ was considered as statistically significant.

\section{RESULTS}

During the study period of one year, 100 patients with AECOPD were admitted at our study center. Among them, 66 patients were females $(66 \%)$ and 34 were males $(34 \%)$. The age of the patients ranged from 50 years to 88 years with mean age $67 \pm 8.41$ yrs.Patient of age $<65$ years were $58 \%$ while $42 \%$ of the patients were of age $>65$ years. Most of the patients were underweight with mean BMI of $19.34 \pm 3.44 \mathrm{~kg} / \mathrm{m} 2$ (Table 1)

Table 1: Baseline characteristics of patients

\begin{tabular}{|c|c|}
\hline Characteristics & Value \\
\hline AGE & $67 \pm 8.41 \mathrm{yrs}$ \\
\hline SEX & \\
\hline Male & 34 \\
\hline Female & 66 \\
\hline SMOKING & \\
\hline Non Smoker & 7 \\
\hline Current smoker & 75 \\
\hline Previous smoker & 18 \\
\hline DURATION OF SMOKING & \\
\hline$<20 \mathrm{yrs}$ & 20 \\
\hline$>20 \mathrm{yrs}$ & 73 \\
\hline BIOMASS EXPOSURE & \\
\hline No Exposure & 41 \\
\hline Exposure & 59 \\
\hline $\mathrm{BMI}(\mathrm{kg} / \mathrm{m} 2)$ & $19.34 \pm 3.44$ \\
\hline $\mathrm{CRP}(\mathrm{mg} / \mathrm{dl})$ & $32.87 \pm 11.65$ \\
\hline $\operatorname{ESR}(\mathrm{mm}$ fall in $1 \mathrm{st} \mathrm{hr}$ ) & $27.6 \pm 7.54$ \\
\hline ARTERIAL BLOOD GAS: & \\
\hline $\mathrm{pH}$ & $7.290 \pm .068$ \\
\hline $\mathrm{pCO} 2 \quad \mathrm{mmHg}$ & $69.34 \pm 12.91$ \\
\hline $\mathrm{pO} 2 \quad \mathrm{mmHg}$ & $67.61 \pm 9.48$ \\
\hline COPD STAGE & \\
\hline Stage I & 8 \\
\hline Stage II & 61 \\
\hline Stage III & 31 \\
\hline
\end{tabular}

Amongour patients 93 (93\%) were smokers. Seventy five patients are current smokers, majority of them smoking for more than 20 pack years. Fifty nine (59\%) of the patients had significant exposure to indoor pollution due to use of biomass fuels and vast majority among them were women. (Table 1) Among the study population, 41 patients were smokers without any exposure to indoor air pollution, 53 patients were smokers with significant exposure to indoor air pollution and only 6 patients were nonsmokers with exposure only to indoor 
air pollution, patients were in COPD stage II (61\%) followed by stage III (31\%). The associated co-morbidities were hypertension in 15 patients; diabetes mellitus in 4 patients \& ischemic heart disease in 10 patients. Presence of comorbidities were associated with prolonged hospitalization in our study. There were 49 patients who were admitted for $\leq 5$ days in hospital, 17 patients were transferred to intensive care unit (ICU) and required mechanical ventilation. There were total 20 deaths during hospitalization.

There was an increase in the level of C-reactive protein with mean value of $32.78 \pm 11.65 \mathrm{mg} / \mathrm{dl}$ in majority of patients.

The arterial blood gas analysis indicated that $95 \%$ of patients had respiratory acidosis with hypoxemia suggesting type II respiratory failure. (Table1) Low $\mathrm{pH}(7.27 \pm 0.085) \mathrm{p}=0.05$, increased $\mathrm{pCO} 2$ (mean $72.10 \pm 14.39) \mathrm{p}=0.029$ and decreased pO2 $(65.04 \pm 8.00) \mathrm{p}=0.05$ were significant predictors for hospitalization $\geq 5$ days in univariate analysis (Table2).

Table 2: Correlation between death \& variables in patients with biomass and smoking (univariate analysis)

\begin{tabular}{|l|l|l|l|}
\hline & Mean & SD & P-Value \\
\hline AGE(yrs) & 69.13 & 7.74 & 3.14 \\
\hline BMI(kg/m2) & 19.15 & 0.20 & 0.777 \\
\hline S. Albumin(gm\%) & 2.965 & 0.48 & 0.693 \\
\hline ESR(mm) & 25.05 & 8.29 & 0.091 \\
\hline CRP(mg/dl) & 35.65 & 11.74 & 0.235 \\
pH & 7.24 & 0.05 & 0.001 \\
\hline pCO2(mmHg) & 76.5 & 13.2 & 0.006 \\
pO2(mmHg) & 68.5 & 9.130 & 0.777 \\
\hline PEFR (L/min) & 153 & 20.59 & 0.487 \\
FEV1/FVC & 0.36 & 0.04 & 0.015 \\
\hline
\end{tabular}

Patients having hypercapnia $\mathrm{pCO} 2(80.24 \pm 10.76 \mathrm{mmHg})$ $\mathrm{p}=0.001, \mathrm{pH}(7.24 \pm 0.062) \mathrm{p}=0.004$ with type II respiratory failure required ICU transfers with mechanical ventilator support and these variables were statistically significant. Patients who were in COPD stage III and with poor arterial blood gas parameters $\mathrm{pH}(7.24 \pm 0.05) \mathrm{p}=0.001, \mathrm{pCO} 2$ $(76.5 \pm 13.12 \mathrm{mmHg}) \mathrm{p}=0.006$ were more prone to die in the hospital. (Table $3 \& 4$ ).
Table 3: Correlation between duration of hospital stay $\geq 5$ days in patients with biomass exposure \& smoker (univariate analysis)

\begin{tabular}{|l|l|l|l|}
\hline & Mean & SD $(\mathbf{9 5} \% \mathbf{C I})$ & P-Value \\
\hline AGE(yrs) & 66.67 & $8.69(50-88)$ & 0.376 \\
\hline BMI(kg/m2) & 19.18 & $3.44(14-26)$ & 0.617 \\
\hline S. Albumin(gm\%) & 2.96 & $0.465(2.3-4.0)$ & 0.215 \\
\hline ESR & 28.43 & $7.10(15-46)$ & 0.263 \\
CRP(mg/dl) & 33.20 & $12.12(8-65)$ & 0.777 \\
\hline pH & 7.278 & $0.085(7.09-7.44)$ & 0.066 \\
\hline pCO2(mmHg) & 72.10 & $14.39(36-97)$ & 0.029 \\
pO2(mmHg) & 65.04 & $8.00(45-84)$ & 0.05 \\
\hline HCO3 & 33.18 & $4.66(23-45)$ & 0.327 \\
\hline HCT & $48.35 \%$ & $4.03(39-57)$ & 0.109 \\
\hline PEFR & 155.31 & $22.11(144-198)$ & 0.743 \\
FEV1/FVC & 0.37 & $0.08(0.29-0.45)$ & 0.321 \\
\hline
\end{tabular}

Table 4: correlations between ICU transfer \& variables in patients with biomass $\&$ smoking (univariate analysis)

\begin{tabular}{|l|l|l|l|}
\hline & MEAN & S D & P-Value \\
\hline AGE(yrs) & 69.13 & $7.74(55-83)$ & 0.373 \\
\hline BMI (kg/m2) & 18.81 & $3.53(14-24)$ & 0.501 \\
\hline S. Albumin(gm\%) & 2.925 & $0.443(2.3-4.0)$ & 0.481 \\
\hline ESR( mm fall in 1 $\left.{ }^{\text {sthr }}\right)$ & 27.38 & $9.14(15-45)$ & 0.897 \\
\hline CRP(mg/dl) & 35.18 & $11.97(8-52)$ & 0.388 \\
\hline pH & 7.24 & $0.062(7.12-7.38)$ & 0.004 \\
\hline pCO2(mmHg) & 80.24 & $10.76(61-97)$ & 0.001 \\
\hline pO2(mmHg) & 64.63 & $10.30(45-84)$ & 0.171 \\
\hline HCO3 & 33.19 & $5.13(23-45)$ & 0.698 \\
\hline PEFR (L/min) & 160.39 & $21.43(123-189)$ & 0.345 \\
\hline FEV1/FVC & 0.37 & $0.08(0.29-0.45)$ & 0.023 \\
\hline
\end{tabular}

Among all the predictors, the stage of COPD was the most important for all the outcomes of interest in multiple logistic regressions (Table 5).

Table 5: Logistic regression analysis of COPD stage iii disease with hospital outcomes

\begin{tabular}{|l|l|l|}
\hline Outcomes & $95 \% \mathrm{CI}$ & P-Value \\
\hline DEATH & $1.161-8.254$ & 0.024 \\
\hline DURATION =5DAYS & $0.158-0.953$ & 0.039 \\
\hline ICU TRANSFER & $1.072-12.695$ & 0.038 \\
\hline MECHANICAL VENTILATION & $1.445-17.379$ & 0.011 \\
\hline
\end{tabular}


use of biomass fuels were 1.64 times more likely to have prolonged hospitalization, 1.08 times more likely to be transferred to ICU with requirement of mechanical ventilation and 1.7 times more likely to die during hospitalizations as compared to the patients with AECOPD who were only smokers. (Table 6)

Table 6: Relative risk of smoker and biomass exposure to the hospital outcome

\begin{tabular}{|l|c|}
\hline Outcome & Relative risk (95\% CI) \\
\hline DURATION $>5$ DAYS & $1.464(0.995-2.154)$ \\
\hline DURATION <5 DAYS & $0.652(0.424-1.003)$ \\
\hline $\begin{array}{l}\text { ICU TRANSFER \& } \\
\text { MECHANICAL } \\
\text { VENTILATION }\end{array}$ & $1.088(0.598-1.982)$ \\
\hline DEATH & $1.708(0.846-3.450)$ \\
\hline
\end{tabular}

\section{DISCUSSION}

We have described the contemporary clinical presentation and demographic of patients presenting with AECOPD at a large tertiary care hospital in Nepal and assessed prospectively the risk factors for duration of hospital stay, ICU transfer and mortality in this cohort of patients. To the best of our knowledge this is the first study of its kind from Nepal. Our study population had more female patients, which is consistent with other studies from this region which also shows high prevalence of smoking \& exposure to indoor air pollution in this gender Clinical presentation of AECOPD observed in the present study was similar to the reports from other parts of the world. ${ }^{6,8,17-21}$

The consistent and important association of increasing severity of COPD ${ }^{1}$ stage (decreasing FEV1) with both the risk of prolonged hospitalization, ICU transfer and death is not surprising and needs no further discussion since low FEV1 was a known prominent risk factor for the mortality from COPD in most epidemiological studies. ${ }^{10-13}$

Presence of coexisting morbidities ${ }^{2}$ were associated with prolonged hospitalization and mortality in our study Bell et $\mathrm{al}^{5}$ had found that coexistent cardiopulmonary disease was a risk factor for prolonged hospitalization in AECOPD and Antonelli Inclazi et al also reported that age and cardiac co morbidity as the best predictors of mortality in the cohort of patients with AECOPD. ${ }^{6}$ Concurring with our results, other authors had also shown that diabetes to be a risk factor for prolonged severe exacerbation, requiring longer periods of hospitalization, associated with isolation of more aggressive bacteria in sputum culture. These results, together with others, suggest that co morbidities appear to be a risk factor for severe life threatening exacerbations that can provoke prolonged hospitalizations, ICU transfer and even cause death, particularly older patients with COPD. We will suggest that special attention to be paid in the management of comorbidities, particularly cardiac dysfunction and diabetes, in patients with AECOPD, and those COPD patients with these co morbidities to be managed more aggressively.

In our study, the patients with abnormal arterial blood gas parameters, ${ }^{3}$ those presenting with decreased $\mathrm{pH}$, increased pCO2 and in COPD stage III had poor hospital outcome. Although $\mathrm{PaCO} 2$ and $\mathrm{HCO} 3$ were not independent predictors of mortality, they tended to be lower in patients who died and the difference was statistically significant. Some of the earlier studies have found blood gas parameters like $\mathrm{pH}^{22}$ and $\mathrm{PaCO}_{2}^{23}$ to be useful in predicting outcome in COPD patients, whereas others did not. ${ }^{19,24,25,27}$ Acute respiratory failure (type II) was a common reason for admission into the ICU in patients with AECOPD. We also observed that need for mechanical ventilation was associated with a poor prognosis. ${ }^{4}$

Overall mortality rate in our study was $20 \%$ which was similar to that reported by Weiss \& Hudson. ${ }^{26}$ The fact, that there were no readmission during the study period, may be because most of the patients might have consulted the local health facility after discharge and were unable to attend our center, due to various reasons. We found that the patients who were smokers and exposed to indoor due to use of biomass fuels had poor outcomes. Exposure to indoor air pollution is a powerful independent predictor for poor prognosis in patients with AECOPD. Our finding also reflects the increasing trends of tobacco smoking and presence of other risk factors associated with chronic respiratory diseases in this population.

Reliable epidemiological data regarding the burden of AECOPD are lacking from Nepal. Even less is known regarding the clinical presentation and outcome of AECOPD in a population with high prevalence of smoking and exposure to indoor air pollution due to use of biomass. The greatest strength of our study lies in the fact that our institution is both primary and tertiary care hospital. Most of these patients were not referred and hence, the clinical spectrum of these patients can be taken as general reflection of the prevalent chronic lung disease in the community. Therefore, the findings from our study can be considered as the surrogate indicator of the state of lung health in our country.

Despite the well-recognized methodological limitation of indirect assessment of indoor air pollution, our study provides 
the evidence that, exposure to indoor air pollution is a powerful independent predictor for poor prognosis in patients with AECOPD. Of particular interest in our study is that prognosis in patients with AECOPD was best predicted by the presence and absence of smoking and exposure to indoor air pollution. This has implication for practicing clinicians as well as policy makers in developing countries with high rates of smoking and use of biomass fuels as source of household energy.

\section{CONCLUSION}

Prospective information collected in a cohort of patients with AECOPD hospitalized in a tertiary care center in Nepal suggest that FEV1 impairment, abnormal arterial blood gas parameters, current smoking status and exposure to indoor air pollution due to use of biomass fuel are associated with prolonged hospitalization, transfer to ICU \& death. The assessment of COPD patients in clinical practice should include these important and easily measurable variables. There is the evidence that exposure to indoor air pollution exerts an additional risk for the mortality in patients presenting with AECOPD.

\section{REFERENCES}

1. National heart, Lung, and blood Institute/World Health Organisation. Global strategy for the Diagnosis Management and Prevention of Chronic Obstructive Pulmonary Disease Workshop Report[ Online].Updated 2004[cited 2005 Aug 10]; Available from:URL http://www.goldcopd.com/workshop/ch3. html.

2. Pande JN, Bhatta N, Biswas D, Pandey RM, Ahluwalia G, Siddaramaiah $\mathrm{NH}$, et al. Outdoor air pollution and emergency room visits at a hospital in Delhi. Indian J Chest Dis Allied Sci. 2002;44(1):13-9. PMid:11845928

3. Newman-Taylor A, Coggon D. Industrial Injuries benefits for coal miners with obstructive lung disease[Letter]. Thorax 1999;54:282. http://dx.doi.org/10.1136/thx.54.3.282

4. Anderson F,Brog S, Jansson AC, Ericsson A, Prutz C, Ronmark $E$, Lundback B: The costs of exacerbation in chronic exacerbation in chronic pulmonary disease(COPD). Respir med 2002;96:700-708. http://dx.doi.org/10.1053/rmed. 2002. 1334

5. Ball P, Harris JM, Lowson D, Tilloston G, Wilson R. Acute Infective Exacerbation of Chronic Bronchitis. QJ Med 1995;88:61-68.
6. Fuso L, Antonelli Inclazi R, Pistelli R, Muzzolon R, Valente $S$, Pagliari $G$ et al. Predecting mortality of patients hospitalized for acutely exacerbated chronic obstructive pulmonary disease. Am J Med 1995; 98:272-277. http://dx.doi.org/10.1016/S00029343(99)80374-X

7. Vilkman S, Keistinen T, Tuuponen T, Kievelu SL. Survival and Cause of death among elderly chronic obstructive pulmonary disease patients after first admission to hospital. Respiration 1997;64:281-284. http://dx.doi.org/10.1159/000196687 PMid:9257363

8. Connors AF Jr, Dawson NV, Thomas C, Harrel FE Jr, Desbiens $N$, Fulkerson WJ et al. Outcomes following acute exacerbation of severe chronic obstructive pulmonary disease. Am J Respir Crit Care Med 1996;154:959-967. http://dx.doi.org/10.1164 / ajrccm.154.4.8887592PMid:8887592

9. Antonelli Inclazi R, Fuso L, De Rosa M, Forastiere F, Rapiti E, Nardecchia $B$ et al. Co- morbidity contributes to predict mortality of patients with chronic obstructive pulmonary disease. Eur Respir J 1997;10:2794-2800. http://dx.doi.org/10. $1183 / 09031936.97 .10122794$

10. Seemungal TAR, Donaldson GC, Paul EA, Bestall JC, Jefferies $D J$, Wedzicha JA. Effect of exacerbation on quality of life in patients with chronic obstructive pulmonary disease. Am J Respir Crit Care Med 1998;157:1418-1422. http://dx.doi.org/ 10.1164/ajrccm.157.5.9709032PMid:9603117

11. Garcia-Aymerich J, Farrer E, Felez MA, Izquierdo J, Marredes RM, Anto JM. On behalf of EFRAM investigators. Risk factors of readmission to hospital for a COPD Exacerbatiom: a prospective study. Thorax 2003;58:100-105. http://dx.doi.org /10.1136/thorax.58.2.100PMid:12554887 PMCid:PMC 1746561

12. Dewan NA, Rafique S, Kanwar B. Acute exacerbation of COPD: Factors associated with poor outcome. Chest 2000; 117:662-671. http://dx.doi.org/10.1378/chest.117.3.662 PMid: 10712989

13. Miravitiles M, Guerrero T, Mayordomo C, Sanchez-Augo L, Nicolau F, Segu JL. Factors associated with increased risk of exacerbation and hospital admission in a cohort of ambulatory COPD; multiple regression analysis. The EOLO study group. Respiration 2000;67:495-501.http://dx.doi.org/10.1159/ 000067462

14. Muratta GH, Gorby MS, Kaspner CO, Chick TW, Halperin AK. A multivariate model for prediction of relapse after outpatient treatment of decompensated chronic obstructive pulmonary disease.Arch Intern Med 1992;152:73-77.http://dx.doi.org/ 10.1001/ archinte. 1992.00400130097011http://dx.doi.org/ 
10.1001 /archinte.152.1.73

15. Loukides S, Polyzogopoulous D. The effect of diabetes mellitus on the outcome of patients with chronic obstructive pulmonary disease exacerbated due to respiratory infections. Respiration 1996;63:170-173. http://dx.doi.org/10.1159/000196539

16. Osman LM, Godden DJ, Friend JAR, Legge JS, Douglas JG. Quality of life and hospital readmission in patients with chronic obstructive pulmonary disease. Thorax 1997;52:67-71. http://dx.doi.org/10.1136/thx.52.1.67 PMid:9039248 PMCid: PMC1758400

17. Khilnani GC, Banga A, Sharma SK. Predictors of mortality of patients with acute respiratory failure secondary to chronic obstructive pulmonary disease admitted to an intensive care unit BMC pul med 2004;12:1417-2466.

18. Seneff MG, Wagner DP, Wagner RP, Zimmerman JE, Kanus WA: Hospital and lyear survival of patients admitted to intensive care units with acute exacerbation of COPD JAMA 1995,274:1852-1857.

19. Porteir F, Defouilloy C, Muir JF. Determinants of immediate survival among chronic respiratory insufficiency patients admitted to an intensive care unit for acute respiratory failure. A prospective multicenter study. The French Task group for acute respiratory failure in chronic respiratory insufficiency. Chest 1992.101:204-210

20. Nevins ML, Epstein SK. Predictors of outcome for patients with COPD requiring mechanical ventilation. Chest 2001. 119: 1840-1849. http://dx.doi.org/10.1378/chest. 119.6.1840 PMid: 11399713

21. Gregoretti $C$, Squadrone V, Fogliati $C$, Oliveri $C$, Navalesi $P$. Transtracheal open ventilation in acute respiratory failure secondary to severe chronic obstructive pulmonary disease exacerbation. Am J Respir Crit Care Med 2006,173: 877-881. http://dx.doi.org/10.1164/rccm.200503-450OCPMid:

\section{6}

22. Warren PM, Flenly DC, Millar JS, Avery A. Respiratory failure revisited: Acute exacerbations of chronic bronchitis between 1961-68 and 1970-76. Lancet 1980,1:467-470. http://dx.doi. org/10.1016/S0140-6736(80)91008-9

23. Breen D, Churches T, Hawker F, Torzillo PJ. Acute Respiratory failure secondary to chronic obstructive pulmonary disease treated in the intensive care unit: a long term follow up study. Thorax 2002, 57:29-33. http://dx.doi.org/10.1136/ thorax. 57.1.29 PMid:11809986 PMCid:PMC1746171

24. Menzies R, Gibbsons W, Goldberg P. Determinants of weaning and survival among patients with COPD who require mechanical ventilation for acute respiratory failure. Chest 1989,95:398-405.http://dx.doi.org/10.1378/chest.95.2.398 PMid:2914493

25. Kaelin RM, Assimacopoulous A, Chevrolet JC. Failure to predict 6- month survival of patients with COPD requiring mechanical ventilation by analysis of simple indices. Chest 1987,92:971-978.http://dx.doi.org/10.1378/chest.92.6.971 PMid:3677842

26. Weiss SM, Hudson LD. Outcome from respiratory failure. Crit Care Clin 1994,10:197-215.PMid:8118729

27. Mohan A, Premananda R, Reddy LN, Rao M, Sharma SK, Kamity R, Bolleneni $S$. Clinical presentation and predictors of outcome in patients with severe acute exacerbation of Chronic Obstructive pulmonary disease requiring admission to intensive care unit. BMC pulmonary medicine 2006, 6:27:14172466 . 